\title{
Distinct susceptibility of developing neurons to death following Bax overexpression in the chicken embryo
}

\author{
N Sato ${ }^{\star,}$, C Sakuma ${ }^{1}$, Y Sato ${ }^{1}$, TW Gould ${ }^{2}$, RW Oppenheim ${ }^{2}$ and \\ H Yaginuma ${ }^{1}$ \\ 1 Department of Neuronatomy \& Embryology, Fukushima Medical University \\ School of Medicine, 1-Hikarigaoka, Fukushima 960-1295, Japan \\ 2 Department of Neurobiology \& Anatomy, and Neuroscience Program, Wake \\ Forest University School of Medicine, Winston-Salem, NC 27157, USA \\ * Corresponding author: N Sato, Department of Anatomy, Fukushima Medical \\ University School of Medicine, 1-Hikarigaoka, Fukushima 960-1295, Japan. \\ Tel: + 8124547 1116; Fax: + 8124549 8811; E-mail: nsato@fmu.ac.jp
}

Received 14.12.04; revised 19.7.05; accepted 29.7.05; published online 09.9.05 Edited by JC Martinou

\begin{abstract}
Bax is a proapoptotic protein that is required for programmed cell death (PCD) of many neuronal populations. Here we show that, during an early period of retinal PCD and in naturally occurring sensory and motor neuron (MN) death in the spinal cord, Bax delivery results in enhanced death of these neural populations. In contrast, Bax overexpression fails to enhance an early phase of MN death that occurs in the cervical spinal cord, although overexpressed Bax appears to be activated in dying MNs. Bax overexpression does not also affect the survival of immature neurons prior to the PCD period. Taken together, these data provide the first in vivo evidence suggesting that Bax appears to act selectively as an executioner only in neurons undergoing PCD. Furthermore, although Bax appears to mediate the execution pathway for PCD, the effect of Bax overexpression on susceptibility to death differs between different neuronal populations.

Cell Death and Differentiation (2006) 13, 435-445.

doi:10.1038/sj.cdd.4401760; published online 9 September 2005
\end{abstract}

Keywords: chick; Bax; cell death; retrovirus; in ovo electroporation; doxycycline

Abbreviations: DRG, dorsal root ganglion; EGFP, enhanced green fluorescent protein; hBax, human Bax; HSP, heat shock protein; MN, motor neuron; PCD, programmed cell death; STS, staurosporine; $\mathrm{VH}$, ventral horn

\section{Introduction}

The $\mathrm{Bcl}-2$ family of proteins are known to regulate the survival and death of various types of cells including neurons. ${ }^{1}$ Individual family members can act to either prevent or promote programmed cell death (PCD). ${ }^{1}$ Bax, a proapoptotic member of the Bcl-2 family, is widely expressed in the nervous system during development ${ }^{2,3}$ and is required for neuronal death since Bax deficiency has been demonstrated to prevent developmental and induced neuronal death. ${ }^{2,4-6}$ Although the necessity of Bax for normal PCD of many neuronal populations during development is well recognized, several questions remain concerning the specific role of Bax in neuronal survival and death in vivo.

In vitro studies have shown that Bax exists in an inactive form when cells are not exposed to apoptotic stimuli but then undergoes translocation and /or conformational changes in response to apoptotic stimuli, which leads to cell death. ${ }^{7-9}$ Cultured sympathetic neurons abundantly express Bax, but nonetheless survive unless trophic factors are removed from the culture medium. ${ }^{2}$ These data indicate that Bax appears to act as an executioner only in cells exposed to death stimuli. On the other hand, the intracellular balance between anti- versus proapoptotic Bcl-2 family members is important in determining whether cells survive or die. ${ }^{3,6,10}$ The balance can be changed in favor of proapoptosis in several pathological conditions which cause neuronal damage. ${ }^{11-13}$ It has been previously reported that overexpression of Bax induces death of cultured neurons in the absence of obvious apoptotic stimuli. $^{3}$ Therefore, the relative levels of Bax expression may in itself be important for regulating cell death in developing neuron even in the absence of extracellular proapoptotic signals.

To address how the post-translational activation of Bax and the levels of Bax expression are involved in survival and death of developing neurons in vivo, we examined the effects of Bax overexpression on different neuronal populations in the chicken embryo. To introduce exogenous Bax into neuronal populations in vivo, we employed two distinct methods, constitutive expression by a noncytopathic avian retroviral vector and inducible expression by in ovo electroporation coupled with tet regulation. We chose to investigate several different types of normal neuronal PCD, including an early phase of retinal PCD, naturally occurring spinal sensory and motor neuron (MN) death, and an early novel type of $\mathrm{MN}$ death in the cervical region. In all these neuronal populations, Bax appears to be activated and acts as a proapoptotic molecule selectively in dying neurons during the normal PCD period. However, whereas Bax overexpression enhances PCD in most populations examined, there was no apparent effect on the early phase of cervical MN PCD. These data reveal an inherent difference in developing neuronal populations in vivo in their susceptibility to undergo apoptosis following Bax overexpression.

\section{Results}

Bax overexpression by a retroviral vector does not affect DF-1 cells in a normal culture condition

To introduce Bax into the chicken embryo, we primarily used an avian replication competent retroviral vector RCASBP with the A subgroup envelope. It is known that infection by avian leucosis-sarcoma viruses with the B- and D-subgroup envelope can lead to the death of avian cells by viral Env-receptor 
interaction, since TVB receptors, identified as cellular receptors for the cytopathic subgroup $B$ and D viruses, appear to be a tumor necrosis factor receptor-related death receptor with a cytoplasmic death domain. ${ }^{14}$ Although we did not detect cytopathic effects of RCASBP viruses with the B subgroup envelope, ${ }^{15}$ to avoid possible extrinsic death signaling by viral Env-receptor interaction, we employed the noncytopathic subgroup A virus $\operatorname{RCASBP}(A)$ for Bax delivery (Figure 1a).

The DF-1 chick fibroblast cell line was known to allow infection and propagation of RCAS viruses efficiently. ${ }^{16,17}$ A few DF-1 cells appeared to undergo PCD $24 \mathrm{~h}$ after the conventional transfection procedure of viral constructs expressing human Bax (hBax). Following several passages, however, DF-1 cells expressing hBax or its fusion protein with enhanced green fluorescent protein (EGFP) could be cultured normally in growth medium although $\mathrm{hBax}$ or EGFP-Bax were abundantly expressed in DF-1 cells (Figure 1b). DF-1 cells did not undergo PCD after infection of RCASBP(A)Bax, suggesting that viral infection is less toxic to cells than plasmid transfection. We also observed dying cells in Bax-transfected cells compared with wild-type or EGFP-transfected cells soon after subculturing procedure. Thus, we assume that Bax overexpression does not affect cell viability unless the cells are stressed. To further examine the effect of Bax expression on DF-1 cells under normal growth conditions, we counted the number of cells following infection of viruses. There were no significant differences in the number of DF-1 cells at any time point between any of the groups examined (Figure 1c). These results indicate that retroviral-mediated Bax overexpression does not alter cell growth, nor does it promote cell death under normal growth conditions.

\section{Bax promotes PCD of DF-1 cells when exposed to death stimuli}

We next examined whether Bax overexpression affects the survival of DF-1 cells exposed to apoptotic stimuli known to induce cell death through Bax-dependent mechanisms. ${ }^{18}$ DF-1 cells expressing Bax or EGFP-Bax underwent cell death more rapidly than control cells when deprived of serum (Figure 1d). When exposed to a kinase inhibitor (staurosporine (STS)), cell death was also induced more efficiently in these Bax-transfected cells than in control cells (Figure 1e). As expected, DF-1 cells expressing $\mathrm{Bcl}-2$ were resistant to STS-induced death (Figure 1e), indicating that expression levels of exogenous genes using this vector are sufficient to act in DF-1 cells.

We then investigated whether foreign Bax is activated in serum-deprived DF-1 cells by using immunocytochemistry. Although Bax immunoreactivity was not clear in healthy cells overexpressing Bax, cells overexpressing EGFP-Bax primarily exhibited a faint, diffuse pattern if cells were healthy (see Figure S1 in the Supplementary material). After $24 \mathrm{~h}$ of serum deprivation, apparent dying cells containing condensed or fragmented nuclei were observed. These cells displayed both an intense, punctate Bax distribution pattern and a diffuse, cytosolic pattern of cytochrome $c$ staining. Caspase- 3 is also activated in these cells. In contrast, apparent non-dying cells a
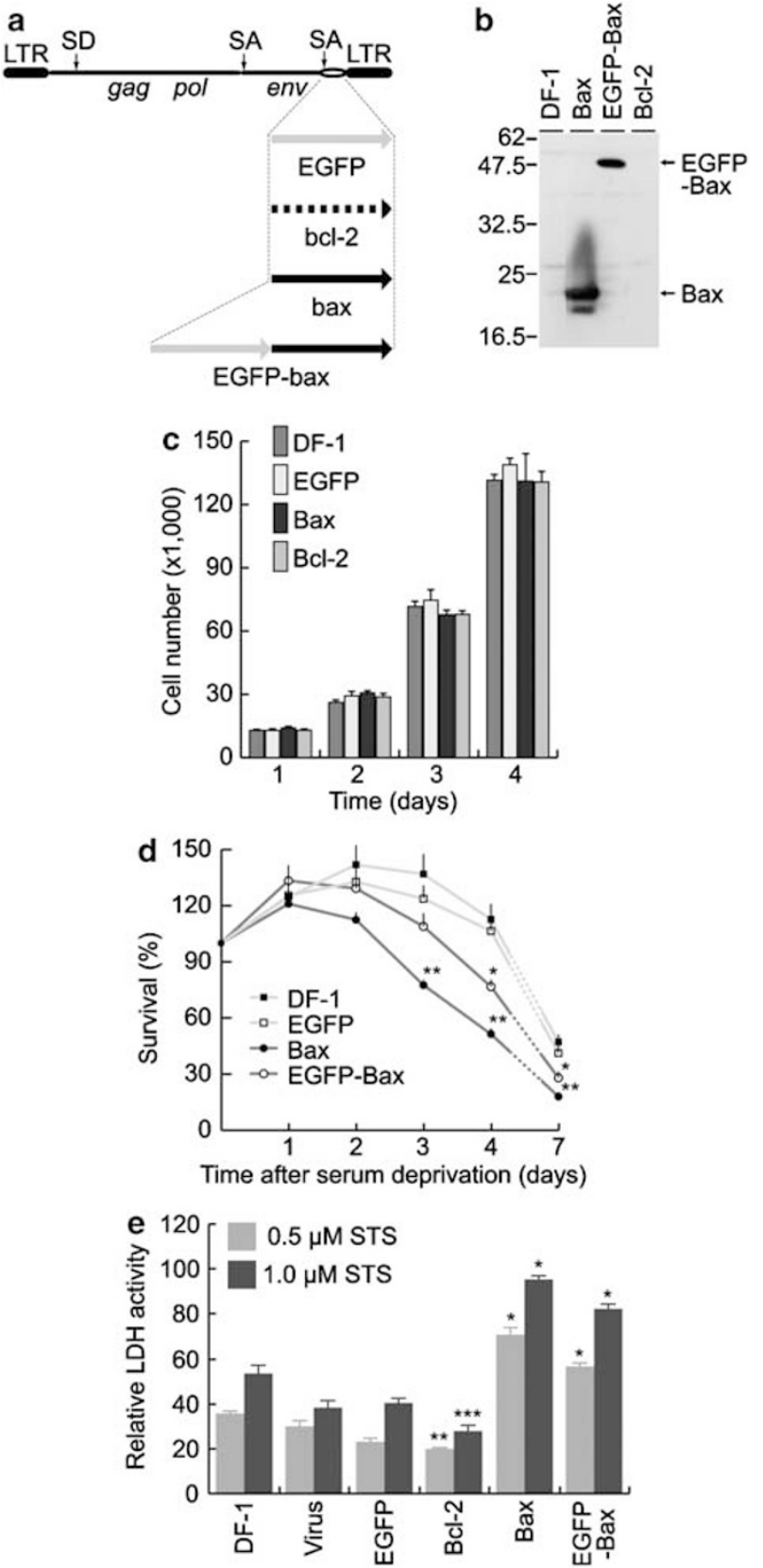

Figure 1 Effects of retroviral-mediated Bax overexpression on DF-1 cells. (a) The structure of the RCASBP retroviral constructs. Genes of interest are placed after the env gene; a subgroup A envelope is used. LTR, long-terminal repeat; $\mathrm{SA}$, splice acceptor; SD, splice donor. (b) Immunoblot with antibody to Bax (Santa cruz, N-20) of whole-cell lysates from DF-1 cells either uninfected or infected with retroviruses expressing Bax, EGFP-Bax or Bcl-2, respectively. (c) Cell growth of DF-1 cells either uninfected or infected with viruses expressing EGFP, Bax or Bcl-2, respectively. Cell numbers (mean + S.E.M., $n=4$ ) are plotted. (d) Time course of DF-1 cell survival after serum deprivation. Living cell numbers (mean + S.E.M., $n=4$ ) are plotted. ${ }^{*} P<0.05,{ }^{* *} P<0.05$ versus DF- 1 or EGFP. (e) Susceptibility of DF-1 cells to STS-induced death. Relative LDH activities (mean \pm S.E.M., $n=6$ ) are plotted. ${ }^{*} P<0.005,{ }^{* \star} P<0.005$, ${ }^{* \star *} P<0.05$ versus DF- 1 , virus, and EGFP

that exhibited intact nuclei and a punctate, mitochondrial cytochrome $c$ staining pattern displayed a diffuse Bax staining pattern (see Figure S1 in the Supplementary material). Thus, 
hBax appears to act in avian cells through its redistribution from a diffuse pattern to a punctate pattern, followed by subsequent activation of caspase-3.

\section{Bax enhances early PCD of developing immature retinal neurons}

The developing chick retina undergoes at least two distinct periods of PCD. ${ }^{19}$ The earlier period of PCD between embryonic day (E) 5 and 7 involves proliferating and migrating immature neurons. In this early phase of PCD, TUNELlabeled cells appeared to be increased in the neural retina of Bax-transfected embryos compared to both controls and EGFP-transfected embryos (Figure 2a-d, j). Activated capase-3 immunoreactivity was also increased in the Bax-transfected retina and its location was identical to the region where a punctate staining pattern of $B a x$ is observed (Figure 2e-h). Infection of RCASBP(A)EGFP-Bax revealed that many dying cells are restricted to the retinal region corresponding to the virus-infected area (Figure $2 \mathrm{i}$ ), suggesting that enhanced PCD is due to Bax overexpression in the neural retina versus in other tissues.

To study the effects of Bax overexpression in the neural retina before the early phase of PCD, we examined the eye cup at E3. At this stage dying cells in the retina were almost exclusively in the optic disc region (Cuadros and Rios ${ }^{20}$ and Figure 2k). Bax overexpression appeared to enhance PCD only in the optic disc region, but did not induce PCD in other areas of the retina although the virus vector was expressed widely over the entire neural retina (Figure 2l, $\mathrm{m}$ ). These results indicate that Bax selectively enhances the death of only those early retinal cell subpopulations which are actively undergoing normal PCD.

\section{Bax enhances naturally occurring neuronal death in the spinal cord}

To further clarify the action of Bax in vivo, we next examined a type of PCD in the spinal cord that involves postmitotic, differentiating cells that have established synaptic connections with target cells and which is regulated by trophic signals. ${ }^{21}$ In this common and well-studied type of PCD, Bax has been shown to be required for the death of both the dorsal root ganglia (DRG) neurons and MNs. ${ }^{4,5,22}$

In control embryos, a small number of TUNEL-labeled cells were detected in both the DRG (Figure 3a) and the ventral horn (VH) (Figure 3d) at E6 when PCD of early differentiating sensory and $\mathrm{MNs}$ is occurring. ${ }^{21}$ In contrast to control embryos, considerably larger numbers of TUNEL-labeled cells were observed in both Bax-transfected DRG neurons (Figure $3 b, c$ ) and MNs (Figure $3 e, f$ ). As observed in the retina, DRG cells and MNs showing a punctate distribution of Bax also express activated caspase-3, suggesting that Bax promotes $\mathrm{PCD}$, at least in part, through caspase activation (Figure $3 g-n$ ). RCASBP viral vectors transduce foreign genes more efficiently into DRG neurons than into ventral MNs. ${ }^{23}$ Following infection of a virus expressing EGFP-Bax, virtually all DRG neurons substantially express EGFP-Bax, whereas MNs exhibit moderate levels of EGFP-Bax expression

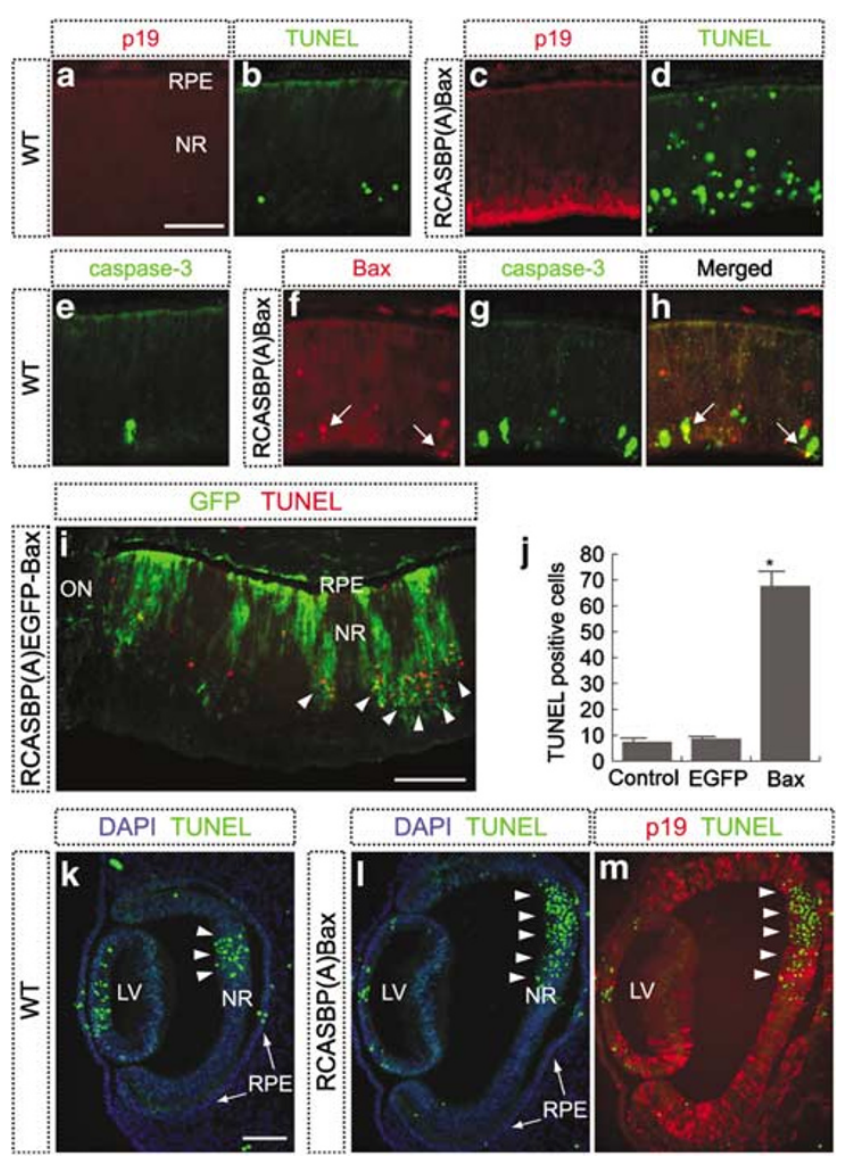

Figure 2 Effect of Bax overexpression on the developing retina. $(\mathbf{a}-\mathbf{j})$ Enhanced early PCD by Bax overexpression in the neural retina. The E6 retinas from a control embryo $(\mathbf{a}, \mathbf{b})$ and a Bax-transfected embryo (c, d) are stained for antiviral gag protein p19 antibody $(\mathbf{a}, \mathbf{c})$ and labeled by TUNEL $(\mathbf{b}, \mathbf{d})$. Similar sections from a control embryo (e) and a Bax-transfected embryo $(\mathbf{f}-\mathbf{h})$ are also labeled with an antiactivated caspase-3 antibody $(\mathbf{e}, \mathbf{g})$ and an anti-Bax antibody (f). Immunostaining for Bax shows a punctuate distribution of Bax (arrows in $\mathrm{f}$ ). A merged image (h) shows a punctuate distribution of Bax corresponding to activated caspase-3 immunoreactivity (arrows in h). Scale bar, $50 \mu \mathrm{m}$. (i) TUNEL labeling for the E7 retina from an embryo infected with an EGFP-Bax vector. TUNEL-labeled nuclei (red) are localized to the identical area exhibiting strong GFP expression (arrow heads). Scale bar, $100 \mu \mathrm{m}$. (j) Quantification by counting numbers of TUNEL-labeled cells in E6 neural retinas. TUNEL-labeled cells present in similar microscope fields (mean \pm S.E.M., $n=6$ ) are plotted. ${ }^{\star} P<0.001$. ( $\left.\mathbf{k}-\mathbf{m}\right)$ Enhanced PCD by Bax overexpression is localized exclusively to a specific region in an early stage of retinal development. The E3 eyes from a control embryo (k) and an embryo infected with a Bax vector $(\mathbf{I}, \mathbf{m})$ are stained against anti-p19 antibody (red), labeled by TUNEL (green), and DAPI (blue). Two-color fluorescent images show TUNEL labeling and DAPI staining (k, I) or TUNEL labeling and immunostaining for $\mathrm{p} 19(\mathbf{m})$. Many TUNEL-labeled cells are localized almost exclusively to the optic disc region in the retina (arrow heads), whereas TUNEL-labeled cells are rare in other areas of the retina, despite widespread virus infection revealed by p19 immunostaining. Scale bar, $100 \mu \mathrm{m}$. $L V$, lens vesicle. NR, neural retina. ON, optic nerve. RPE, retinal pigment epithelium

(Figure 30). However, the vast majority of DRG neurons are healthy at E5 and exhibit a diffuse pattern of EGFP-Bax (Figure 3o), whereas a small number of DRG neurons exhibit a typical punctate pattern and undergo PCD as revealed by fragmented nuclei (Figure 3p). Moreover, although levels of Bax expression are completely different between DRG and 

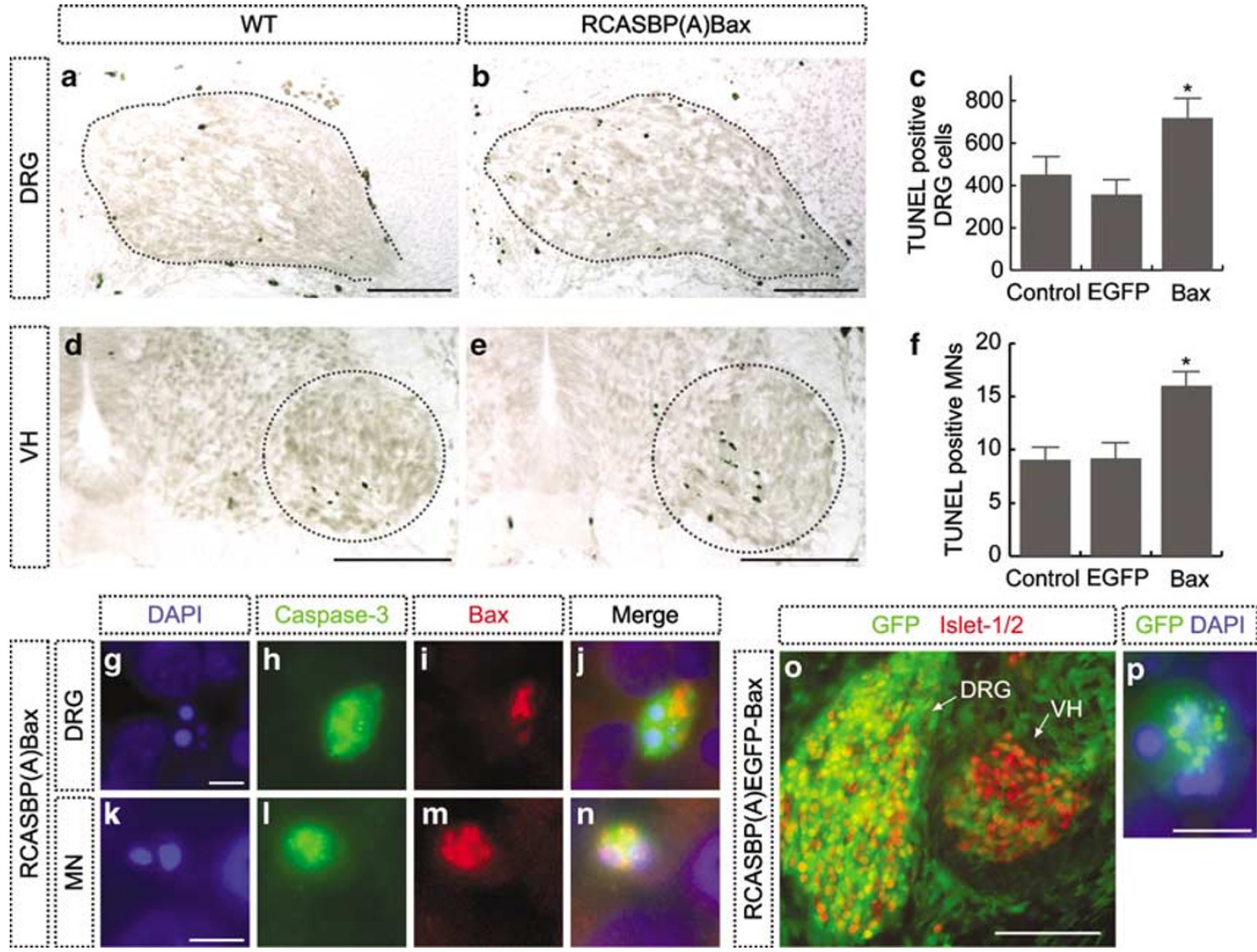

Figure 3 Effect of Bax overexpression on the developing spinal cord. (a-c) Enhanced PCD of sensory neurons in the DRG by Bax overexpression. The L3 DRG from a control embryo (a) and a Bax-transfected embryo (b) are labeled by TUNEL (brown). Dotted lines indicate the DRG. Scale bar, $100 \mu \mathrm{m}$. (c) Quantification by counting numbers of TUNEL-labeled cells in the E6 DRGs. TUNEL-labeled cells present in the L3 DRG (mean \pm S.E.M., $n=6$ ) are plotted. ${ }^{\star} P<0.05$. (d-f) Enhanced PCD of spinal MNs by Bax overexpression. The LMC from a control embryo (d) and a Bax-transfected embryo (e) are labeled by TUNEL (brown). Dotted circles indicate the LMC. Scale bar, $100 \mu \mathrm{m}$. (f) Quantification by counting numbers of TUNEL-labeled cells in the E6 LMCs. TUNEL-labeled cells per section in the L3 LMC (mean \pm S.E.M., $n=6$ ) are plotted. ${ }^{*} p<0.005$. ( $\left.\mathbf{g}-\mathbf{n}\right)$ Bax immunoreactivity in dying neurons. Sensory $(\mathbf{g}-\mathbf{j})$ and motor $(\mathbf{k}-\mathbf{n})$ neurons from a Bax-transfected embryo are labeled with the antiactivated caspase-3 antibody (green), the anti-Bax antibody (red), and with DAPI (blue; $\mathbf{g}, \mathbf{k}$ ). Merged images (j, $\mathbf{n}$ ) demonstrate identical neurons showing a punctuate Bax distribution, caspase-3 activation, and fragmented nuclei. Scale bars, $5 \mu \mathrm{m}$. (o) Delivery of EGFP-Bax (green) into the spinal cord at E5. DRG neurons and MNs are labeled with an anti-lslet-1/2 antibody (red). Scale bar, $100 \mu \mathrm{m}$. (p) EGFP-Bax displaying a punctuate pattern of distribution (green) in a DRG cell with fragmented nuclei (DAPI; blue). Scale bar, $5 \mu \mathrm{m}$

MNs, Bax overexpression enhances the death of both populations during the PCD period (Figure $3 a-f$ ).

We next examined immature neurons before the period of normal PCD. ${ }^{21}$ Few, if any, TUNEL-labeled cells in either the DRG or VH were observed in either control or Bax-transfected embryos on E3 prior to the normal period of PCD in the developing spinal cord (see Figure $S 2$ in the Supplementary material). In contrast, TUNEL-labeled cells appeared to be increased by Bax overexpression in the dorsal region of the spinal cord where cells, including the neural crest, are located that undergo normal PCD at this stage of development (ref. ${ }^{24}$ and see Figure S2 in the Supplementary material).

We also examined whether Bax overexpression affected the target cells of DRG neurons such as developing skin and the dorsal horn of the spinal cord. Although the Bax vector was expressed in both the spinal cord and skin (see Figure S3 in the Supplementary material), the number of TUNEL-labeled cells in these regions were similar in control and Baxtransfected embryos (see Figure S3 in the Supplementary material). The muscle targets of MNs also appear to develop similarly in control and Bax-transfected embryos (data not shown). Thus, the enhanced PCD of sensory and MNs is not likely due to target cell perturbation, but rather to the direct action of hBax in sensory and MNs. Taken together, these data indicate that Bax overxpression does not induce the death of cells in neuronal populations in vivo which do not undergo normal PCD, but rather only increases the death of neuronal populations that are in the process of normal developmental PCD.

\section{Cells that would normally survive the period of PCD undergo apoptosis following Bax overexpression}

To determine whether enhanced PCD observed in Baxtransfected embryos represents an acceleration versus an increase in the overall magnitude of PCD, cell numbers were counted after the period of PCD. In the retinal ganglion cell layer at E9, there was a $10-20 \%$ increased loss of cells in the 
a
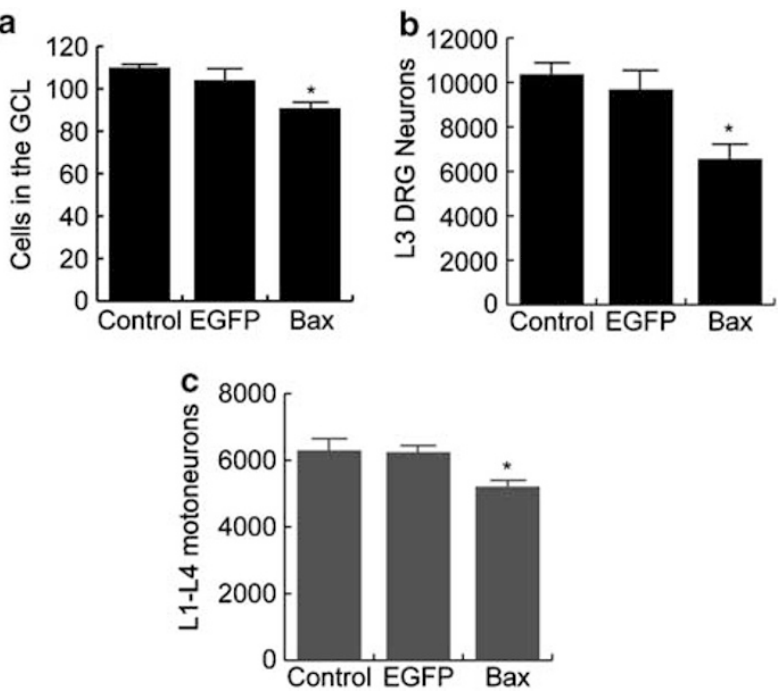

Figure 4 Decrease in the number of surviving retinal ganglion (GCL) cells, DRG neurons, and MNs by Bax overexpresion after the period of PCD. (a) Quantification by counting numbers of cells in the GCL on E9. Cell numbers in the GCL per microscope field at $\times 1000$ (mean \pm S.E.M., $n=6$ ) are plotted. Error bars represent S.E.M. ${ }^{*} P<0.05$ versus Control and EGFP. (b) Quantification by counting numbers of DRG neurons on E15.5. Sensory neuron numbers in the L3 $\mathrm{DRG}$ (mean \pm S.E.M., $n=6$ for control and EGFP, $n=9$ for Bax) are plotted. ${ }^{*} P<0.05$ versus control and EGFP. (c) Quantification by counting numbers of MNs on E9.5. MN numbers in the L1-L4 segments (mean \pm S.E.M., $n=8$ ) are plotted. ${ }^{\star} P<0.05$ versus control and EGFP

Bax-transfected embryos (Figure 4a). Similarly, Bax overexpression resulted in a $30-40 \%$ decrease in the number of the L3 DRG neurons at E15 (Figure 4b). Finally, Baxtransfected embryos exhibited $15-20 \%$ fewer lumbar MNs on E9.5 compared with control embryos (Figure 4c). Thus, PCD enhanced by Bax overexpression involves the death of neurons that would normally survive.

\section{Bax fails to enhance early MN death in the cervical spinal cord}

In addition to the typical target-dependent naturally occurring MN death observed at relatively late stages (E6-10) of spinal cord development, another type of MN death occurs only in the cervical region of the spinal cord between E4 and E5. ${ }^{25} \mathrm{At}$ E4.5 when this early PCD occurs in the $\mathrm{VH}$ of the cervical spinal cord, there is no significant difference in the number of TUNEL-labeled cells in control versus Bax-transfected embryos (Figure 5a). By contrast, Bcl-2 overexpression with this same vector clearly reduces the number of TUNELlabeled cells (Figure 5a). Moreover, Bax delivery into lumbar MNs clearly shows an increase of TUNEL-labeled cells during the later PCD period (Figure 3f). Thus, the absence of increased PCD in the cervical MNs on E4.5 of Bax-transfected embryos is not likely due to an insufficient level of Bax expression (Figure 5a).

To examine whether Bax overexpression results in death of immature cervical MNs prior to the onset of normal PCD on $\mathrm{E} 4.5$, we counted the number of MNs at E4. There were no significant differences in the number of MNs between any of the groups examined (Figure 5b). This indicates that Bax overexpression neither induces cell death in young MNs nor affects the number of MNs generated prior to the onset of $\mathrm{PCD}$. The number of $\mathrm{MNs}$ in Bax-transfected embryos after the period of cervical $\mathrm{MN}$ death was also comparable to control embryos (Figure $5 \mathrm{c}$ ). Therefore, we conclude that, in contrast to retinal cells, DRG cells, and lumbar MNs, retroviral-mediated Bax overexpression does not alter early $\mathrm{PCD}$ of MNs in the cervical spinal cord of the chicken embryo.

We next asked whether Bax immunoreactivity occurs in dying MNs. Consistent with cell counts, similar number of MNs exhibited fragmented nuclei and caspase- 3 activation in the $\mathrm{VH}$ of the cervical spinal cord of control and Bax-transfected embryos (Figure 5d,e,h,i). In contrast to control embryos, however, many cells in the $\mathrm{VH}$ of the Bax-transfected embryos exhibit a punctate Bax staining pattern as was observed in the retina, the DRG, and lumbar MNs at later developmental stages (Figure 5f, j). Most of these cells also contained either fragmented nuclei or caspase-3 activation, suggesting that hBax is, in fact, activated in dying cervical MNs (Figure 5k). When EGFP-Bax is delivered into cervical MNs, many cells show a diffuse distribution of EGFP-Bax (Figure 5I, m), although a few MNs exhibit a punctate pattern, together with fragmented nuclei or caspase-3 activation (Figure $5 \mathrm{I}, \mathrm{n}$ ). Thus, hBax appears to be activated selectively in dying MNs.

\section{Inducible expression of gain-of-function Bax mutants, but not naive Bax, enhances the early cervical MN death}

Although retroviral-mediated Bax delivery clearly enhances the death of lumbar MNs, the level of Bax expression in spinal MNs is generally lower than in the retina or the DRG (Figures $2 \mathrm{i}, 30$ ); moreover, the RCASBP retroviral vector induces global transgene expression in the chick (see Figure S2 in the Supplementary material). Accordingly, to introduce Bax specifically into MNs during the period of early PCD, we have used in ovo electroporation ${ }^{26}$ coupled with the tet regulatory system. $^{23}$ To target gene expression to spinal MNs, the reverse tetracycline-controlled transactivator is expressed under the control of the MN-specific HB9 promoter. $^{27}$ We successfully controlled GFP expression spatially and temporally in MNs by administration of doxycycline (see Figure S4 in the supplementary material).

When EGFP-Bax was introduced into cervical MNs by this method, the ratio of healthy MN to dying MN was similar to that from control embryos transfected with GFP alone (Figure 6a, $b, d)$. These data are consistent with those described above using the viral delivery model. Thus, it seems likely that the lack of enhanced PCD is not due to low levels of Bax expression in cervical MNs. We also generated Bax mutants, S184A and dS184, which are derived from mutation of Ser184 and appear to function as gain-of-function mutants. ${ }^{8}$ These EGFP-Bax mutants significantly increased the ratio of dying MNs compared with GFP and EGFP-Bax (Figure 6a, c, e). Both EGFP-Bax and the mutants display a punctate cellular pattern with caspase-3 activation in dying MNs (Figure 6f, g). These results suggest that foreign naive Bax is not active in those cervical MNs that would normally survive the early PCD 
a

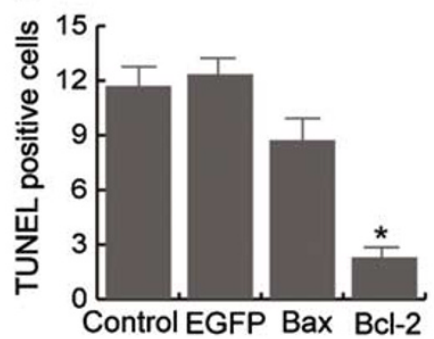

b

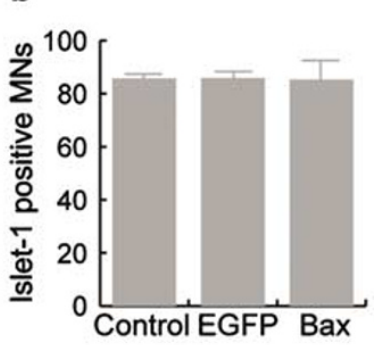

C

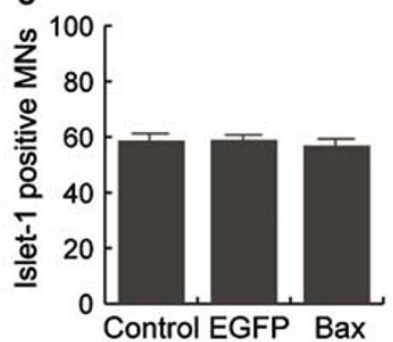

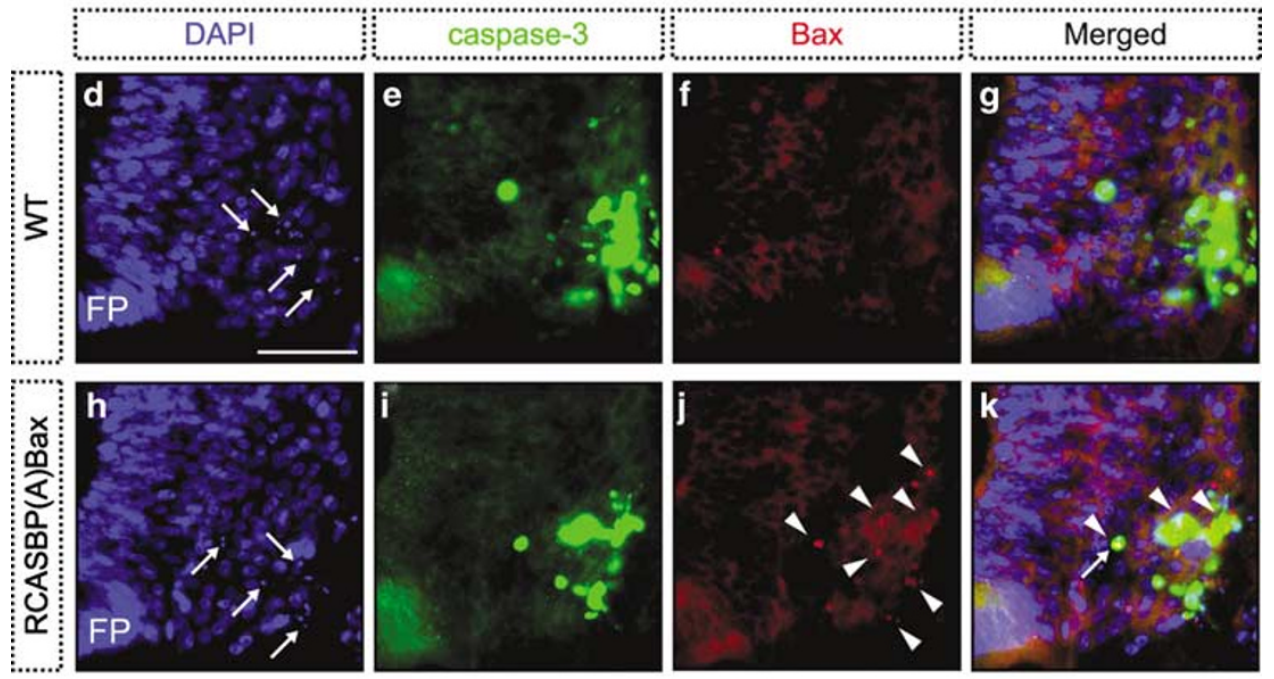
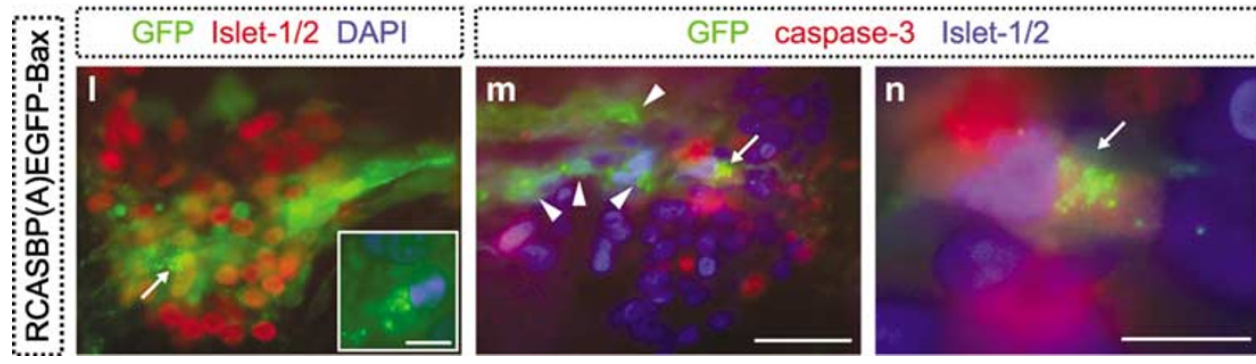

Figure 5 Effect of Bax overexpression on developing MNs in the cervical spinal cord. FP, floor plate. (a) Quantification by counting numbers of TUNEL-labeled cells in the VH of cervical spinal cord on E4.5. TUNEL-labeled MNs per section through the cervical (c) segment C10-11 (mean \pm S.E.M., $n=8$ for control, Bax, and Bcl-2, $n=12$ for EGFP) are plotted. ${ }^{*} P<0.0005$. (b) Quantification by counting numbers of MNs on E4. Islet-1/2 immunoreactive cells in the VH of the C10-11 spinal cord per section (mean + S.E.M., $n=6$ ) are plotted. (c) Quantification by counting numbers of MNs on E5.5. Islet-1/2 immunoreactive cells in the VH of the C10-11 spinal cord per section (mean \pm S.E.M., $n=6$ ) are plotted. (d-n) Bax activation in the VH of the cervical spinal cord. The VH of the cervical spinal cord from a control embryo (d-g) and a Bax-transfected embryo (h-k) are labeled with an anti-activated caspase-3 antibody (green; e,i), an anti-Bax antibody (red; f, j), and with DAPI (blue; $\mathbf{d}, \mathbf{h}$ ). Fragmented nuclei (arrows in d,h) and activation of caspase-3 are similarly shown in a control and a Bax-transfected embryo. Bax immunostaining shows a punctuate distribution (arrow heads in j). Merged image (k) from a Bax-transfected embryo demonstrates cells double-labeled with anti-Bax antibody and antiactivated caspase-3 (arrow heads), and a cell showing punctuate Bax immunoreactivity, caspase-3 activation, and fragmented nuclei (arrows). Scale bar in (d) $50 \mu \mathrm{m}$. (I) Delivery of EGFPBax into MNs in the cervical spinal cord on E4.5. MNs are labeled with an anti-Islet-1/2 antibody. Most MNs show a diffuse localization of EGFP-Bax, but a small population displays a punctuate pattern (an arrow; a higher magnification image is shown in the inset). Scale bar in the insect in I, $5 \mu \mathrm{m}$. ( $\mathbf{m}, \mathbf{n}$ ) Caspase-3 activity in MNs expressing EGFP-Bax. The VH from an EGFP-Bax transfected embryo is labeled with an anti-lslet-1/2 antibody (blue) and an antiactivated caspase-3 antibody (red). Most MNs showing a diffuse localization of EGFP-Bax are not associated with caspase-3 activation (arrow heads), whereas a small population displaying a punctuate Bax pattern also exhibit caspase-3 activation (arrow; a higher magnification image is shown in $\mathbf{n}$ ). Scale bar in $\mathbf{m}, 30 \mu \mathrm{m}$. Scale bar in $\mathbf{n}, 10 \mu \mathrm{m}$

period, whereas a similar MN population undergoes death by constitutively active Bax gain-of-function mutants.

To clear MN population in which hBax is activated, we next examined the expression of LIM homeodomain transcription factors that define different types of MNs. ${ }^{28}$ We focused on LIM homeodomain genes Lim-3, because dying population appears to be a subgroup of MN that lacks the expression of Lim-3 (Yaginuma et al., unpublished). Prior to the onset of PCD (E4), both Lim-3-positive and -negative MNs showed a diffuse distribution of EGFP-Bax (Figure 7a, b), suggesting that inactive $\mathrm{hBax}$ is introduced into both populations. During the PCD period (E4.5), Lim-3-positive MNs displayed a diffuse 
a
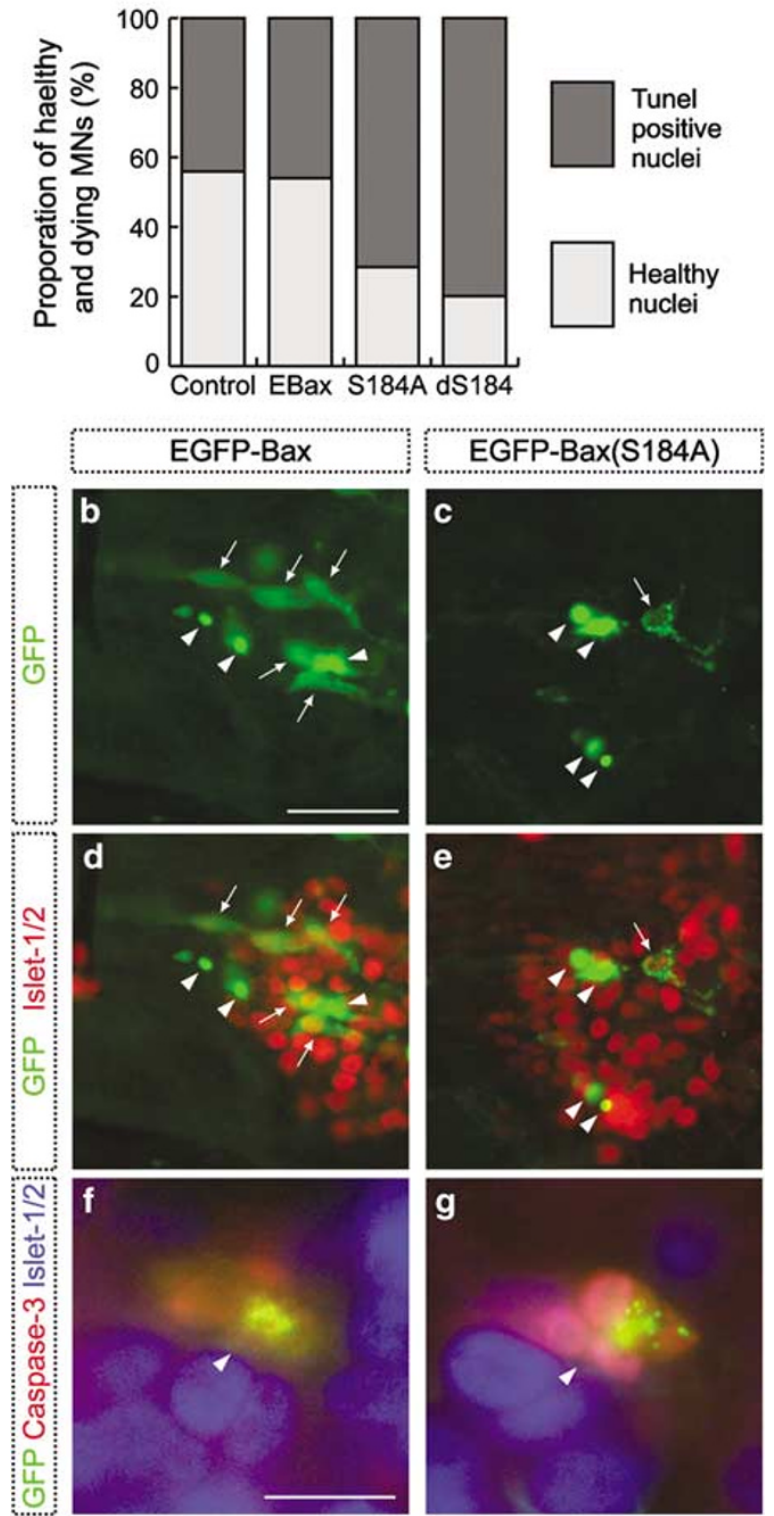

Figure 6 Effects of Bax and Bax mutant expression on cervical MN death. (a) Comparison of the ratio of healthy MN to dying MN. EGFP, EGFP-Bax, EGFPBax(S184A), and EGFP-Bax(dS184) are induced in cervical MNs during the early PCD period by Dox administration. Nuclei of cervical MNs are labeled with an anti-Islet-1/2 antibody and TUNEL. Cells expressing GFP are included as either healthy MNs (Islet-1/2 positive) or dying MNs (TUNEL positive). More than 200 MNs from three different embryos were counted in each experimental group. The experiment was repeated twice with similar results. (b-e) Dox-mediated expression of Bax and Bax mutants in cervical MNs during the period of PCD. Arrows indicate diffuse distribution of $\mathrm{Bax}$ (green; $\mathbf{b}, \mathbf{c}$ ) which are Islet-1/2positive MNs (red; $\mathbf{d}, \mathbf{e}$ ), whereas arrowheads indicate a punctate and condensed pattern of Bax distribution $(\mathbf{b}, \mathbf{c})$ in cells which lose Islet-1/2 immunoreactivity. Scale bar, 50 ím. (f, $\mathbf{g})$ A punctate pattern of EGFP-Bax (f) or EGFP$\operatorname{Bax}(\mathrm{S} 184 \mathrm{~A})(\mathbf{g})$ is similarly accompanied by caspase-3 activation (red arrowheads). Scale bar, $10 \mu \mathrm{m}$

distribution of EGFP-Bax with intact nuclei (Figure 7c, d). By contrast, MNs exhibiting a punctate pattern of hBax lacked Lim-3 immunoreactivity (Figure 7e, f). At E4.5 we checked six embryos (at least 15 cervical sections per embryo) and failed

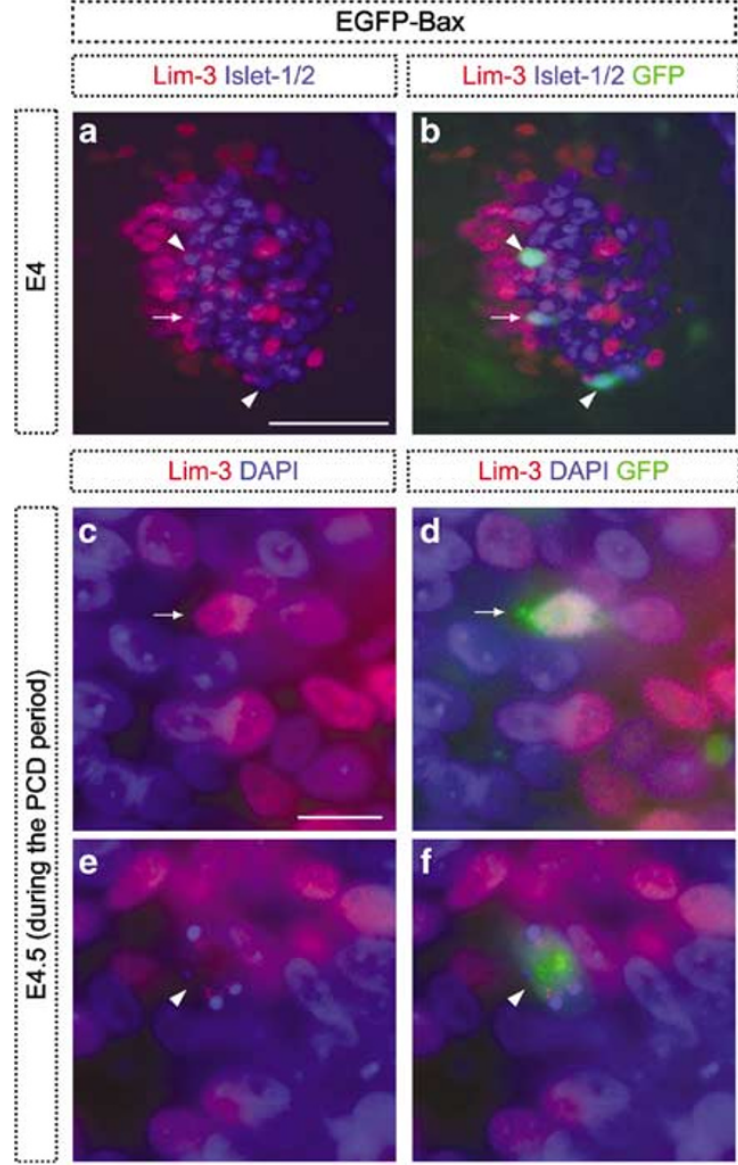

Figure 7 Activation of Bax in a subclass of MNs which do not express Lim-3. (a, b) Dox-mediated expression of Bax in cervical MNs prior to the onset of PCD (E4). The EGFP-Bax-introduced VH is labeled with an anti-lslet-1/2 antibody (blue) and an anti-Lim-3 antibody (red). Both Lim-3-positive (an arrow) and negative (arrow heads) MNs (a) exhibit diffuse distribution of Bax (b). Scale bar, $50 \mu \mathrm{m}$. (c-f) Dox-mediated expression of Bax in cervical MNs during the period of PCD (E4.5). The EGFP-Bax-introduced VH is labeled with DAPI (blue) and an anti-Lim-3 antibody (red). A Lim-3-positive MN (arrows) displays an intact nucleus (c) with diffuse distribution of Bax (d). In contrast, a Lim-3-negative MN (arrow heads) exhibits a fragmented nucleus (e) with a punctate pattern of Bax (f). Scale bar, $10 \mu \mathrm{m}$

to find Lim-3-positive MNs with a punctate pattern of hBax and fragmented nuclei. Thus, Bax activation appears to occur in cervical MNs that lack the expression of Lim-3.

\section{Discussion}

Bax is known to be inactive when cells are not exposed to apoptotic stimuli, but then undergoes translocation and/or conformational changes in response to apoptotic stimuli, which results in the release of mitochondrial proteins (such as cytochrome $c$ ) and leads to cell death. ${ }^{7-9,18}$ Previous studies have shown that cells overexpressing Bax proliferate normally ${ }^{29}$ and undergo PCD after death stimuli by conformational changes of Bax, resulting in its translocation to mitochondria. ${ }^{7}$ Moreover, sympathetic neurons express high levels of bax mRNA, yet will not undergo PCD unless deprived 
of growth factors. ${ }^{2}$ Other studies pointed out that the expression of Bax increases during PCD, as well as under pathological conditions. ${ }^{3,6,10-13}$ In the present studies, we initially examined the effects of Bax overexpression on several different neuronal populations that undergo normal PCD. These include the early phase of developing retinal PCD which appears to be induced by death signaling through NGF and TGF- $\beta,{ }^{30,31}$ as well as the common type of neuronal PCD that occurs in developing sensory and MNs of the spinal cord after forming synaptic connections with targets. ${ }^{32}$ In these populations, Bax enhanced normal PCD, but by contrast did not cause the death of cells in populations prior to the onset of normal PCD. Dying neurons, but not healthy neurons, displayed a punctate Bax distribution pattern accompanied by caspase- 3 activation. Our results are consistent with previous in vitro studies showing that Bax is a potent proapoptotic molecule for developing neurons undergoing $P C D$, and provide the first in vivo evidence that Bax is inactive in developing neurons that are not undergoing PCD. Thus, although increased expression of Bax may also be a factor for PCD, apoptotic signaling appears to be required for Bax activation in vivo and post-translational activation of Bax is essential for neurons to die.

It has long been known that a significant proportion of cells in many neuronal populations undergo PCD during development, whereas other neurons in the same population can survive throughout development and into adulthood. ${ }^{32}$ In vertebrates, it has been recognized that extrinsic signals derived from cell-cell interactions, such as target-derived trophic signals, are critically involved in regulating how many neurons in an apparently homogenous population survive or die. In the present study, especially in the DRG, the cellular sources of extrinsic trophic signals appeared to be largely unaffected by Bax overexpression, since the main source of trophic factors (target tissues), including the skin and the dorsal spinal cord, were not perturbed (see Figure S3 in the Supplementary material). If sufficient amounts of extrinsic trophic signals completely define the number of surviving neurons, then it would be expected that Bax overexpression would primarily accelerate the death of the sub-population of neurons destined to die. However, a proportion of neurons that would normally survive also underwent PCD following Bax overexpression (Figure 4). Thus, in these neuronal populations, susceptibility to death can be changed by the levels of Bax expression. Based on the observation that active death signaling is required for Bax to act as a proapoptotic molecule, such signaling is likely to be transmitted to both neurons fated to die as well as to those that would normally survive (Figure 8). Interestingly, although virtually all neurons were infected with a Bax vector (Figures 2c, 3o), a majority of neurons can still survive the period of PCD (Figure 4). Collectively, these data suggest that individual neurons in a population may not be homogeneous, but rather may differ in their vulnerability to undergo PCD by virtue of differences in their intracellular machinery and/or environment. Previous studies suggested that a balance between anti- versus proapoptotic $\mathrm{Bcl}-2$ family members determine the susceptibility of cells to die. ${ }^{3,6,10}$ Other cellular factors such as heat shock protein (HSP) 27 may be involved in regulating survival and death of neurons. ${ }^{33}$ Thus, whether a neuron lives or dies
The early phase of retinal PCD \& naturally occurring death of the spinal sensory and motor neurons

Prior to the PCD period During the PCD period
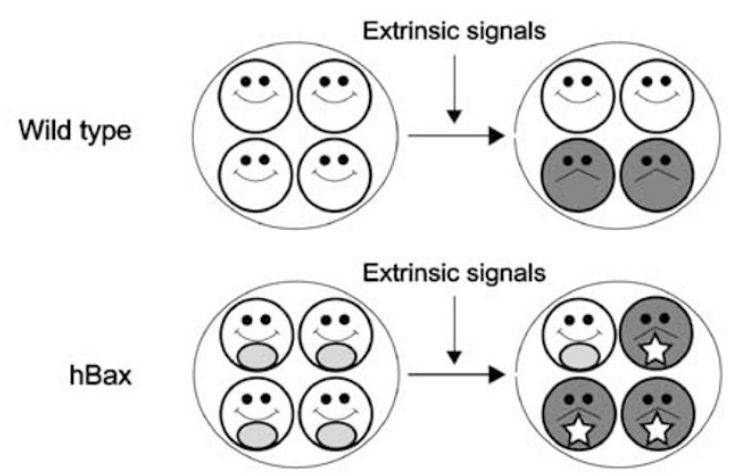

The early motor neuron death in the cervical region

Prior to the PCD period During the $P C D$ period
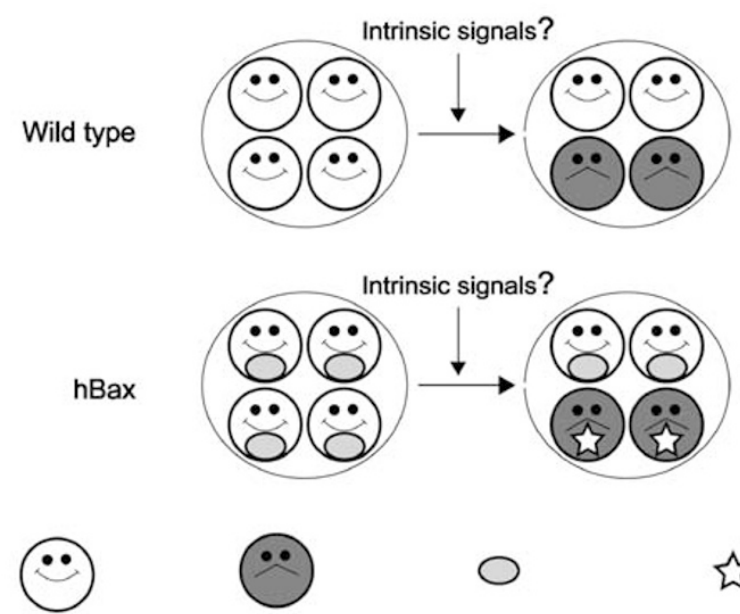

Living neuron
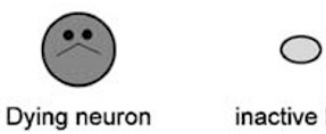

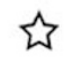

Figure 8 Summary of Bax action in developing neuronal populations in vivo. During early retinal PCD and the period of naturally occurring death of DRG and MNs, the decision to die or survive is regulated by extrinsic factors. Bax overexpression does not affect these neurons prior to the PCD period, but enhances death through activation of Bax during the PCD period. In contrast, Bax overexpression does not affect the survival of spinal MNs in the cervical region either prior to or during the early PCD period, although Bax appears to be activated in dying cervical MNs. These findings suggest that death signaling is required for the effects of Bax on these neurons in vivo. The mechanism for the decision to die or survive in cervical spinal MN during this early phase of PCD is currently unclear. But intrinsic factors (e.g. Lim-3) may be involved in the process

during the period of developmental PCD may be regulated by both extrinsic (e.g., neurotrophic factors) and intrinsic (e.g. Bcl-2 members, HSP27, etc) signals.

It has long been recognized that the later PCD of MNs in the spinal cord occurring between $E 6$ and $E 10$ is regulated by target-derived signals. ${ }^{32}$ By contrast, the earlier phase of MN death (E4-E5) occurs independent of target-derived trophic signals. ${ }^{25}$ Recent studies demonstrated that this early MN 
death is accompanied by caspase-3 activation and can be prevented by $\mathrm{Bcl}-2$, suggesting that both early and later $\mathrm{MN}$ death may involve a similar execution pathway. ${ }^{15,34-36}$ However, in the present study, we found that Bax overexpression does not enhance this early cervical MN death, even though hBax appears to be activated in dying MNs which exhibit caspase- 3 activation. These results suggest that the lack of an enhancement of PCD in cervical MNs by Bax overexpression is not likely due to a distinct execution pathway that is independent of Bax. Rather, putative death signals may affect only a restricted subpopulation of cervical MNs, whereas other MNs in the same population fail to undergo Bax activation (even though Bax is substantially expressed) because of the lack of death signals (Figure 8). Gain-of-function mutants of Bax clearly enhanced the death of early cervical MNs (Figure 6). Since these constitutively active mutants also result in caspase-3 activation, the downstream execution pathway following Bax activation appears to be conserved in the subpopulation of MNs that would normally survive the early $\mathrm{PCD}$ period. As a previous study suggested that this PCD is controlled independent of peripheral targets, the fate of individual MNs in the cervical spinal cord may be intrinsically determined. ${ }^{25}$ We recently found that dying population appears to be a subgroup of MN that lacks the expression of LIM homeodomain genes Lim-3, and introduction of this transcription factor rescues cervical MN from early PCD (Yaginuma et al., unpublished). Present data show that Bax is inactive in Lim-3-positive MNs (Figure 7). Collectively, although overexpression studies must always be interpreted cautiously, our data suggest that death signals that mediate Bax activation appear to be transmitted to a limited population (Lim-3-negative MNs). By contrast, in other populations examined (e.g., retina, DRG, lumbar MNs), death-inducing signals may be widely transmitted to all or most neurons in the population. Although these differences may be the basis for the distinct susceptibility to die following Bax overexpression among cells in different neuronal populations, further in vivo studies examining the selective deletion or inactivation of Bax in these different populations are needed to more definitively test this idea.

\section{Materials and Methods}

\section{Constructs and virus generation}

To generate retroviral plasmids carrying Bax, the hBax cDNA was initially cloned into the adaptor plasmid Slax $13 \mathrm{Nco}$, and subsequently cloned into the RCASBP(A) retroviral plasmid. ${ }^{37}$ For the GFP-fusion constract, Bax was initially cloned into the C2-EGFP plasmid (Clontech). Then, the EGFPBax fragment was cloned into the Slax13Nco plasmid, and finally cloned into the RCASBP $(A)$ plasmid. High-titer viruses were generated by standard procedures with only minor modification. ${ }^{15,23}$ Briefly, virus propagation was initiated by transfection of retroviral plasmid constructs into the DF-1 chick fibroblast cell line. ${ }^{16,17}$ After several passages of DF-1 cells, the supernatants were collected and concentrated by centrifugation at $22000 \mathrm{rpm}$ for $3 \mathrm{~h}$ in a Beckman SW 28 rotor and stored in aliquots at $-80^{\circ} \mathrm{C}$. Typical virus titers were $1-5 \times 10^{8} \mathrm{cfu} / \mathrm{ml}$.

The reverse tetracycline-controlled transactivator was placed into the Ascl/Xbal site on a HB9 plasmid. Bax mutants were generated by standard PCR. The following primers were used in the PCR: introducing an Xhol site for the N-terminus, $5^{\prime}$ - ttaattcctcgagcatggacgggtccggggagca$3^{\prime}$; an EcoRI site for the C-terminus of the dS184 mutant, $5^{\prime}$ - gcgtcagaa ttctcagcccatcttcttccagatggtgagggcggtgagcac- $3^{\prime}$; and the S184A mutant $5^{\prime}$ - gcgtcagaattctcagcccatcttcttccagatggtgagcgcggcggtgagcac-3'. These mutants were cloned into the pEGFP-C2 vector. Then, EGFP, EGFP-Bax, EGFP-Bax(dS184), and EGFP-Bax(S184A) were cloned into the pTRETight vector (Clontech).

\section{Cell culture, immunoblotting, and cell growth assay}

DF-1 cells were cultured in DMEM high-glucose medium (Gibco) containing $10 \%$ fetal bovine serum (FBS, Sigma). DF-1 cells were infected with each of the viruses at 50 infectious units per cell. After a few passages of the DF-1 cells, immunoblotting was performed as described previously, ${ }^{23}$ using the polyclonal anti-Bax antibody N-20 (Santa Cruz). For cell growth assays, cells were initially plated at a density of $6 \times 10^{3}$ cells/well in 12-well tissue culture plates (Greiner). After 1 day later, cells were infected with each of the viruses at 50 infectious units/cell. Cell counts were performed every $24 \mathrm{~h}$ following viral infection. The MannWhitney test was used for statistics unless otherwise noted.

\section{Cell viability assay}

Transfected cells were plated in four-well petri dishes (Greiner) and cultured in DMEM containing 10\% FBS for 1 day. After being washed with PBS, growth medium was replaced with serum-free medium. The number of surviving cells in each well was counted for a week. The number of surviving cells immediately after serum deprivation was considered as the $100 \%$ value. Alternatively, transfected cells were plated at a density of either $5 \times 10^{3}$ or $2.5 \times 10^{3}$ per well in 96 -well tissue culture plates. After being cultured in growth medium for 1 day, cells were washed with PBS and cultured in either serum-free medium or medium supplemented with $1 \%$ FBS and $0.5-1 \mu \mathrm{M}$ STS for $24 \mathrm{~h}$. Supernatants were collected from each well and lactate dehydrogenase activity was measured as described by the manufacturer (Roche).

\section{Chicken embryo, virus infection, and in ovo electroporation}

White Leghorn chicken eggs were purchased from Takeuchi poultry farm (Nara, Japan) and incubated at $37.6^{\circ} \mathrm{C}$ in a humidified incubator. Early embryos were staged according to Hamburger and Hamilton. ${ }^{38}$

Viruses were injected into embryos at stage 9 (E1.5) via a pulled micropipette needle as described. ${ }^{15,23}$ Typically, a total of $0.2-0.5 \mu \mathrm{l}$ of virus solution was injected into a lumen of the neural tube.

Plasmids were injected into a lumen of stage 13-14 (E2-2.5) chick spinal cords. Electroporation was performed using a square wave electroporator (CUY21EDIT) as described elsewhere. ${ }^{26}$ Doxycycline (10 $\mu \mathrm{g}$; Sigma) was added at 24 and again at $36 \mathrm{~h}$ after electroporation, and embryos were harvested at $48 \mathrm{~h}$ (E4.5) after electroporation.

\section{Immunohistochemistry, cell death assay, and quantification of neuron numbers}

Immunohistochemistry was performed as described previously. ${ }^{15,23,34}$ Primary antibodies used in this study were the anti-Islet-1/2 (clone 4D5, Developmental Studies Hybridoma Bank, DSHB), anti-Lim-3 (clone 67.4E12, DSHB), antiviral p19 GAG protein (clone AMV-3C2, DSHB), antiactivated caspase-3 (clone C92-605, Pharmingen), and anti-Bax 
(clone 4F11, MBL). We tested three distinct antibodies for $\mathrm{hBax}$ from either Santa Cruz (polyclonal antibody, N-20), MBL (monoclonal antibody, $4 \mathrm{~F} 11$ ), or Pharmingen (polyclonal antibody). All these antibodies specifically recognized $\mathrm{hBax}$ in tissue sections and appeared to fail to react with endogenous chicken Bax. As sections reacted with $4 \mathrm{~F} 11$ antibody displayed lower background staining, we used $4 \mathrm{~F} 11$ antibody to detect foreign Bax in the tissue sections. Dying cells were observed by either TUNEL staining or detection of activated caspase-3, as described previously. ${ }^{15} \mathrm{DRG}$ neurons were counted in every fifth section through the third lumber segment (L3) using hematoxylin-eosin-stained sections as described previously. ${ }^{21}$ Retinal ganglion cells were counted in five different microscope fields at $\times 1000$ magnification in the naso-central region of horizontal sections of the retina, which contains the optic nerve. Lumbar (L) MNs were counted in every fifth section through the L1-L4 segments using thionin-stained sections as described previously. ${ }^{21}$ To quantify MN numbers per spinal cord section, Islet-1/2 immunoreactive neurons in the $\mathrm{VH}$ were counted in every fifth section through the C10-11 cervical segment with segment boundaries identified relative to adjacent DRGs.

\section{Acknowledgements}

This work is supported by Grant-in-Aid for Scientific Research (14580731, $15590165,16500223,17590167)$ and by the Fukushima Society for the Promotion of Medicine, by the $\mathrm{NIH}$ (NS020402) and by a grant from the Robert Packard ALS Center of Johns Hopkins University. We wish to thank the Department of Anatomy for its generous support. We also thank $\mathrm{H}$. Ohuchi for technical assistance, S. H. Hughes for a RSV-derived retroviral plasmid $\operatorname{RCASBP}(A), B$. A. Morgan for an adaptor plasmid Slax13Nco, S. L. Pfaff for a HB9 promoter plasmid, and Y. Tsujimoto for the human bax cDNA.

\section{References}

1. Merry DE and Korsmeyer SJ (1997) Bcl-2 gene family in the nervous system. Annu. Rev. Neurosci. 20: 245-267

2. Deckwerth TL, Elliott JL, Knudson CM, Johnson Jr EM, Snider WD and Korsmeyer SJ (1996) BAX is required for neuronal death after trophic factor deprivation and during development. Neuron 17: 401-411

3. Vekrellis K, McCarthy MJ, Watson A, Whitfield J, Rubin LL and Ham J (1997) Bax promotes neuronal cell death and is downregulated during the development of the nervous system. Development 124: 1239-1249

4. White FA, Keller-Peck CR, Knudson CM, Korsmeyer SJ and Snider WD (1998) Widespread elimination of naturally occurring neuronal death in Bax-deficient mice. J. Neurosci. 18: 1428-1439

5. Sun W, Gould TW, Vinsant S, Prevette D and Oppenheim RW (2003) Neuromuscular development after the prevention of naturally occurring neuronal death by Bax deletion. J. Neurosci. 23: 7298-7310

6. Shindler KS, Latham CB and Roth KA (1997) Bax deficiency prevents the increased cell death of immature neurons in bcl-x-deficient mice. J. Neurosci. 17: 3112-3119

7. Wolter KG, Hsu YT, Smith CL, Nechushtan A, Xi XG and Youle RJ (1997) Movement of Bax from the cytosol to mitochondria during apoptosis. J. Cell Biol. 139: 1281-1292

8. Nechushtan A, Smith CL, Hsu YT and Youle RJ (1999) Conformation of the Bax C-terminus regulates subcellular location and cell death. EMBO J. 18 : 2330-2341

9. Putcha GV, Deshmukh M and Johnson Jr EM (1999) BAX translocation is a critical event in neuronal apoptosis: regulation by neuroprotectants, BCL-2, and caspases. J. Neurosci. 19: 7476-7485

10. Vogelbaum MA, Tong JX and Rich KM (1998) Developmental regulation of apoptosis in dorsal root ganglion neurons. J. Neurosci. 18: 8928-8935
11. Paradis E, Douillard H, Koutroumanis M, Goodyer C and LeBlanc A (1996) Amyloid beta peptide of Alzheimer's disease downregulates $\mathrm{BCl}-2$ and upregulates bax expression in human neurons. J. Neurosci. 16: 7533-7539

12. Vukosavic S, Dubois-Dauphin M, Romero N and Przedborski S (1999) Bax and Bcl-2 interaction in a transgenic mouse model of familial amyotrophic lateral sclerosis. J. Neurochem. 73: 2460-2468

13. O'Dell DM, Raghupathi R, Crino PB, Eberwine JH and McIntosh TK (2000) Traumatic brain injury alters the molecular fingerprint of TUNEL-positive cortical neurons in vivo: a single-cell analysis. J. Neurosci. 20: 4821-4828

14. Brojatsch J, Naughton J, Rolls MM, Zingler K and Young JA (1996) CAR1, a TNFR-related protein, is a cellular receptor for cytopathic avian leukosissarcoma viruses and mediates apoptosis. Cell 87: 845-855

15. Sato N, Sakuma $C$, Kato $H$, Milligan $C E$, Oppenheim RW and Yaginuma $H$ (2002) Bcl-2 rescues motoneurons from early cell death in the cervical spinal cord of the chicken embryo. J. Neurobiol. 53: 381-390

16. Himly M, Foster DN, Bottoli I, lacovoni JS and Vogt PK (1998) The DF-1 chicken fibroblast cell line: transformation induced by diverse oncogenes and cell death resulting from infection by avian leukosis viruses. Virology 248 : 295-304

17. Schaefer-Klein J, Givol I, Barsov EV, Whitcomb JM, VanBrocklin M, Foster DN, Federspiel MJ and Hughes SH (1998) The EV-O-derived cell line DF-1 supports the efficient replication of avian leukosis-sarcoma viruses and vectors. Virology 248: 305-311

18. Wei MC, Zong WX, Cheng EH, Lindsten T, Panoutsakopoulou V, Ross AJ, Roth KA, MacGregor GR, Thompson CB and Korsmeyer SJ (2001) Proapoptotic BAX and BAK: a requisite gateway to mitochondrial dysfunction and death. Science 292: 727-730

19. Frade JM, Bovolenta $P$, Martinez-Morales JR, Arribas A, Barbas JA and Rodriguez-Tebar A (1997) Control of early cell death by BDNF in the chick retina. Development 124: 3313-3320

20. Cuadros MA and Rios A (1988) Spatial and temporal correlation between early nerve fiber growth and neuroepithelial cell death in the chick embryo retina. Anat. Embryol 178: 543-551

21. Caldero J, Prevette D, Mei X, Oakley RA, Li L, Milligan C, Houenou L, Burek M and Oppenheim RW (1998) Peripheral target regulation of the development and survival of spinal sensory and motor neurons in the chick embryo. J. Neurosci. 18: 356-370

22. Patel TD, Jackman A, Rice FL, Kucera J and Snider WD (2000) Development of sensory neurons in the absence of NGF/TrkA signaling in vivo. Neuron 25 345-357

23. Sato N, Matsuda K, Sakuma C, Foster DN, Oppenheim RW and Yaginuma $\mathrm{H}$ (2002) Regulated gene expression in the chicken embryo by using replicationcompetent retroviral vectors. J. Virol. 76: 1980-1985

24. Homma S, Yaginuma H and Oppenheim RW (1994) Programmed cell death during the earliest stages of spinal cord development in the chick embryo: a possible means of early phenotypic selection. J. Comp. Neurol. 345: 377-395

25. Yaginuma H, Tomita M, Takashita N, McKay SE, Cardwell C, Yin QW and Oppenheim RW (1996) A novel type of programmed neuronal death in the cervical spinal cord of the chick embryo. J. Neurosci. 16: 3685-3703

26. Itasaki N, Bel-Vialar S and Krumlauf R (1999) 'Shocking' developments in chick embryology: electroporation and in ovo gene expression. Nat. Cell Biol. 1 E203-E207

27. Thaler J, Harrison K, Sharma K, Lettieri K, Kehrl J and Pfaff SL (1999) Active suppression of interneuron programs within developing motor neurons revealed by analysis of homeodomain factor HB9. Neuron 23: 675-687

28. Tsuchida T, Ensini M, Morton SB, Baldassare M, Edlund T, Jessell TM and Pfaff SL (1994) Topographic organization of embryonic motor neurons defined by expression of LIM homeobox genes (see comment). Cell 79: 957-970

29. Oltvai ZN, Milliman CL and Korsmeyer SJ (1993) Bcl-2 heterodimerizes in vivo with a conserved homolog, Bax, that accelerates programmed cell death. Cell 74: 609-619

30. Frade JM, Rodriguez-Tebar A and Barde YA (1996) Induction of cell death by endogenous nerve growth factor through its $p 75$ receptor. Nature 383 : 166-168

31. Dunker N, Schuster N and Krieglstein K (2001) TGF-beta modulates programmed cell death in the retina of the developing chick embryo. Development 128: 1933-1942

32. Oppenheim RW (1991) Cell death during development of the nervous system. Annu. Rev. Neurosci. 14: 453-501 
33. Benn SC, Perrelet D, Kato AC, Scholz J, Decosterd I, Mannion RJ, Bakowska $\mathrm{JC}$ and Woolf CJ (2002) Hsp27 upregulation and phosphorylation is required for injured sensory and motor neuron survival. Neuron 36: 45-56

34. Yaginuma H, Shiraiwa N, Shimada T, Nishiyama K, Hong J, Wang S, Momoi T, Uchiyama Y and Oppenheim RW (2001) Caspase activity is involved in, but is dispensable for, early motoneuron death in the chick embryo cervical spinal cord. Mol. Cell. Neurosci. 18: 168-182

35. Sato N, Wang S, Li L, Okabe K, Hashimoto M, Yaginuma H, Mikoshiba K, Uchiyama Y, Uetsuki T, Yoshikawa K, Milligan CE and Oppenheim RW (1998) A novel strategy for introducing exogenous bcl-2 into neuronal cells: the Cre/
loxP system-mediated activation of bcl-2 for preventing programmed cell death using recombinant adenoviruses. Mol. Cell. Neurosci. 12: 65-78

36. Oppenheim RW, Flavell RA, Vinsant S, Prevette D, Kuan CY and Rakic P (2001) Programmed cell death of developing mammalian neurons after genetic deletion of caspases. J. Neurosci. 21: 4752-4760

37. Morgan BA and Fekete DM (1996) Manipulating gene expression with replication-competent retroviruses. Methods Cell Biol. 51: 185-218

38. Hamburger V and Hamilton HL (1992) A series of normal stages in the development of the chick embryo. 1951. [see comment]. Dev. Dyn. 195: 231-272

Supplementary Information accompanies the paper on Cell Death and Diffrentiation website (http://www.nature.com/cdd). 